\title{
Avian Influenza in Live Bird Markets in the Suez Canal region, Egypt
}

\section{Amira M. Helal ${ }^{1 *}$, Abdel Satar Arafa ${ }^{2}$, Hanan F. Abdien ${ }^{3}$, Dalia M. Hamed ${ }^{3}$ and Mohsen Z. El Dimerdash $^{3}$}

\author{
${ }^{1}$ National laboratory for veterinary quality control on poultry production, Animal Health \\ Research Institute, Ismailia, Egypt \\ ${ }^{2}$ National laboratory for veterinary quality control on poultry production, Animal Health \\ Research Institute, Dokki, Giza, Egypt \\ ${ }^{3}$ Avian and Rabbit Medicine Department, Faculty of Veterinary Medicine, Suez Canal \\ University, Ismailia, Egypt
}

Article History: Received: 4/6/2017 Received in revised form: 30/10/2017 Accepted: 10/11/2017

\begin{abstract}
Avian influenza causes severe economic losses in poultry industry and endangers human life. This study aimed to detect avian influenza viruses (AIVs) in live bird markets (LBMs) in the Suez Canal region. Tracheal and cloacal swabs were collected from apparently healthy birds (152 chickens, 119 ducks, 44 geese and 60 turkeys) from live bird markets in Ismailia, Portsaid and Suez Governorates during the period from January to December 2014. Our results revealed that AIVs prevalence was $4.3 \%$ in the surveyed markets. The H9 low pathogenic (LPAI) positive birds $(56.3 \%)$ were higher than H5 highly pathogenic (HPAI) infected cases $(43.8 \%)$, while no $\mathrm{H} 7$ positive cases were detected. The positive cases in turkeys, chickens, geese, and ducks were $6.7 \%, 5.3 \%, 4.6 \%$, and $1.7 \%$ respectively. Additionally, the highest frequencies were recorded in cold weather during the winter season $2.4 \%$. Our investigation verified that live bird markets in the Suez Canal region continue to be high risk locations for AIVs due to the existence of various AIV subtypes (H5 and H9) in poultry species from different breeding sectors in Egypt. This mixing permits transmission of the disease from infected areas to non-infected ones. In addition, the coexistence of both H5 and H9 subtypes in the same poultry population may provide an opportunity for genetic reassortment and emergence of novel viruses. Consequently, birds in LBMs are incriminated in the continuous circulation of AIVs, therefore representing a main source of AI infection to commercial poultry and householders. Thus, control actions towards AIVs should include live bird markets as a critical threat source of the disease transmission.
\end{abstract}

Keywords: Avian Influenza, Live Bird Markets, Suez Canal.

\section{Introduction}

Avian influenza virus (AIV) is a devastating virus causing enormous losses in the poultry industry worldwide [1]. AIVs are segmented negative-sense ssRNA viruses belonging to the family Orthomyxoviridae that is divided into five genera, including influenza types $\mathrm{A}, \mathrm{B}$, and $\mathrm{C}$, Isavirus and Thogotovirus [2]. Only influenza type A viruses infect poultry, and they are subdivided into subtypes based on the antigenic relationships of the surface glycoprotein hemagglutinin (HA) and neuraminidase (NA). There are 18 haemagglutinin (HA) and 11 neuraminidase (NA) subtypes; the recent subtypes H17N10 and H18N11 were detected in bats [3,4].

In Egypt, highly pathogenic AIV (HPAIV) H5N1 has been circulating in domestic poultry since February 2006 [5] and was declared endemic in July 2008 [6]. The recent wave of H5N1 AIVs in Egypt during 2014-2015, showed a dramatic increase of H5N1 infections in poultry and humans. The H5N1 incidence increased over 400 outbreaks in both commercial and backyard poultry [7]. An alarming increase of $\mathrm{H} 5 \mathrm{~N} 1$ human cases was also reported from November 2014 to March 2015, where, 47 out of 159 new human cases were fatal. Therefore, Egypt recorded the first highest number of confirmed human infections and deaths during 2014 and 2015 [8]. Additionally, as of July 2016, HPAIV H5N1 caused 117 fatal human cases out of 354 infected individuals [9]. The first report in Egypt described the isolation and identification of H9N2 virus was in May 2011

*Corresponding author email: (dr.amirahelal @ yahoo.com), National laboratory for veterinary quality 340 control on poultry production, Animal Health Research Institute, Ismailia, Egypt. 
from commercial quail flock in Giza Province [10]. The H9N2 AIV is common in chickens, ducks and other poultry species. It can sometimes cross the species barrier and cause human infections, which has raised public health concerns [11]. The disease in humans is usually subclinical [12], and H9N2 interspecies transmission from avian to mammalian hosts could happen due to the presence of human virus-like receptor specificity in H9N2 from poultry [13].

Live bird markets (LBMs) are considered the most serious points in the poultry value chain, as they link commercial, small-scale household farms, slaughter houses, producers, traders and consumers [14]. In Egypt poultry meat trade depends mainly on LBMs due to insufficient slaughterhouses, lack of marketing infrastructure, and cultural preference for the consumption of freshly slaughtered poultry [15]. Nearly, 16000 LBMs in Egypt sell live or freshly slaughtered birds to consumers, besides over 4300 small slaughtering and defeathering points sell freshly slaughtered or chilled birds [16]. Abdelwhab et al. [15] documented the wide circulation of H5N1 AIV in LBMs in Egypt. Backyard waterfowl can act as a reservoir and/or source of $\mathrm{A} / \mathrm{H} 5 \mathrm{~N} 1$ especially in LBMs [17], because these markets provide optimal conditions for amplifying and sustaining virus circulation and could thus, become viral reservoirs themselves [18].

The goal of this study was to investigate the role of LBMs in the continuous circulation of AIVs in the Suez Canal region. The role of bird species and the season on the AI viruses dissemination was determined.

\section{Materials and Methods}

\section{Samples}

Tracheal and cloacal swabs were collected from apparently healthy domestic poultry species (chicken, ducks, geese and turkeys) at different LBMs in the Suez Canal region including Ismailia, Suez and Port Said during the period from January to December 2014 (Table 1). All swab samples were collected in 1-2 mL phosphate Buffer Saline (PBS) tubes as transport media (PH 7-7.4) containing antibiotics, according to OIE manual [19]. The tubes were then placed in ice bags and transported quickly to the laboratory and then were preserved at $-80{ }^{\circ} \mathrm{C}$ until tested [19]. For sample preparation, a pool of tracheal and cloacal swabs ( 1 to 10 swabs of the same bird species and source) was dispensed in $1.5-3$ $\mathrm{ml}$ plastic screw capped tubes.

Table 1: Collected tracheal and cloacal swabs from live bird markets in the Suez Canal region during 2014

\begin{tabular}{lccccc}
\hline & & \multicolumn{2}{c}{ Species } & \multicolumn{2}{c}{ Total } \\
Governorate & Chicken & Duck & Geese & Turkey & \\
\cline { 2 - 5 } Ismailia & 49 & 41 & 15 & 18 & 123 \\
Suez & 51 & 40 & 16 & 20 & 127 \\
Port Said & 52 & 38 & 13 & 22 & $\mathbf{6 0}$ \\
Total & $\mathbf{1 5 2}$ & $\mathbf{1 1 9}$ & $\mathbf{4 4}$ & $\mathbf{6 0}$ & \\
\hline
\end{tabular}

\section{Real-time reverse-transcription polymerase chain reaction ( $R T-q P C R)$}

RNA was extracted from a mix of tracheal and cloacal samples using QIAamp Viral RNA Mini Kit (Qiagen, Valencia, Calif., USA) following the manufacturer's instructions, then subjected to real time reverse transcription polymerase chain reaction (RT-qPCR) targeting AIV matrix gene. Positive samples were further subtyped for detection of the H5, $\mathrm{H} 7$ and $\mathrm{H} 9$ genes. The test was performed in a Stratagene MX3005P real time PCR machine.

Primers and probe used in RRT-PCR for Matrix gene were M24 (5'-AGA TGA GTC 
TTC TAA CCG AGG TCG -3') and M25 (5'TGC AAA AAC ATC TTC AAG TCT CTG3'), probe (6-FAM-TCA GGC CCC CTC AAA GCC GA-TAMRA) [20]. Primers and probe for H5 subtype were H5 LH1 (5'-ACA TAT GAC TAC CCA CAR TAT TCA G -3') and H5 RH1 (5'-AGA CCA GCT AYC ATG ATT GC - 3'), H5 probe (6-FAM-TCW ACA GTG GCG AGT TCC CTA GCA-TAMRA) [20]. Primers and probe for $\mathrm{H} 7$ subtype were LH6 H7(5'-GGC CAG TAT TAG AAA CAA CAC CTA TTG A-3') and RH4 H7 (5'-GCC CCG AAG CTA AAC CAA AGT AT-3'), H7 Probe (6-HEX-CCG CTG CTT AGT TTG ACT GGG TCA ATC T-BHQ) [21]. Primers and probe for $\mathrm{H} 9$ subtype were $\mathrm{H} 9 \mathrm{~F}$ ( $5^{\prime}$-GGA AGA ATT AAT TAT TAT TGG TCG GTA
C-3') and H9R (GCC ACC TTT TTC AGT CTG ACA TT), H9 probe (6- CY5-AAC CAG GCC AGA CAT TGC GAG TAA GAT CCTAMRA) [22]. Thermal profile and cycling condition of Matrix gene detection was done by Reverse transcription at $50^{\circ} \mathrm{C}$ for $30 \mathrm{~min}$, followed by Primary denaturation step at $95^{\circ} \mathrm{C}$ for $15 \mathrm{~min}$ and secondary denaturation at $95^{\circ} \mathrm{C}$ for 30 second then annealing and extension at $60^{\circ} \mathrm{C}$ for 20 second. While, thermal profile and cycling condition of $\mathrm{H} 5, \mathrm{H} 7$ and $\mathrm{H} 9$ genes detection was done by reverse transcription at $50^{\circ} \mathrm{C}$ for $30 \mathrm{~min}$, followed by Primary denaturation step at $95^{\circ} \mathrm{C}$ for $15 \mathrm{~min}$ and secondary denaturation at $94^{\circ} \mathrm{C}$ for 15 second then annealing at $54^{\circ} \mathrm{C}$ for 30 second and extension at $72^{\circ} \mathrm{C}$ for 10 second.

Table 2: Avian influenza prevalence in different species in live bird markets in the Suez Canal region during 2014

\begin{tabular}{lccc}
\hline Species & $\begin{array}{c}\text { RRT-PCR results for M gene } \\
\text { (positive/total tested of each species) }\end{array}$ & $\begin{array}{c}\text { Positive cases subtype } \\
\text { (positive/total positive) }\end{array}$ \\
\cline { 3 - 4 } Chickens & $8 / 152(5.3 \%)$ & H5 & H9 \\
Ducks & $2 / 119(1.7 \%)$ & $2 / 2(100 \%)$ & $0 / 2(0 \%)$ \\
Geese & $2 / 44(4.6 \%)$ & $2 / 2(100 \%)$ & $0 / 2(0 \%)$ \\
Turkeys & $4 / 60(6.7 \%)$ & $2 / 4(50 \%)$ & $2 / 4(50 \%)$ \\
Total & $\mathbf{1 6 / 3 7 5 ( 4 . 3 \% )}$ & $\mathbf{7 / 1 6 ( 4 3 . 8 \% )}$ & $\mathbf{9 / 1 6 ( 5 6 . 3 \% )}$ \\
\hline
\end{tabular}

\section{Results and Discussion}

Live bird markets (LBMs) facilitate the spread of avian influenza viruses to poultry and humans particularly women selling birds in traditional markets and children participating in removal of wastes and offal in retail shops [15]. Consequently, LBMs have played a key role in the persistence of infection [23]. In this study, low AIV prevalence was recorded in the examined birds at LBMs (4.3\%) (Table 2); this might be attributed to that poultry sellers do not present the diseased poultry for selling at markets. Abdelwahab et al. [15] recorded that 5.6\% of the examined LBMs were positive for AI in the Canal region from January to April 2009.
In the examined markets, the $\mathrm{H} 9$ positive cases were higher than $\mathrm{H} 5 \quad(56.3 \%$ and $43.8 \%$, respectively) (Table 2). The $\mathrm{H} 9$ positive cases are usually associated with subclinical infection since the H9 AIV was reported to be of low pathogenicity in chickens [24] causing mild clinical signs [25]. Moreover, H9 AIV is known to negatively affect poultry health generally and increase the danger of infections of H5N1 HPAI which is already endemic in Egypt [26]. This ascertains that only apparently healthy birds are presented in markets, while, those with H5 subtype infection show clinical signs rendering them from sale in markets. 
Table 3: Seasonal prevalence of avian influenza viruses in live bird markets in the Suez Canal region during 2014

\begin{tabular}{lc}
\hline Season & $\begin{array}{c}\text { AIVs prevalence } \\
\text { (positive/total tested cases) }\end{array}$ \\
\hline Winter & $9 / 375(2.4 \%)$ \\
Spring & $2 / 375(0.5 \%)$ \\
Summer & $2 / 375(0.5 \%)$ \\
Autumn & $3 / 375(0.8 \%)$ \\
\hline "Winter
\end{tabular}

"Winter: December, January, and February; Spring: March, April, and May; Summer: June, July, and August;

Autumn: September, October, and November

Regarding poultry species, the highest positive cases were detected in turkeys and chickens $6.7 \%$ and $5.3 \%$ respectively (Table 2 ). These results might be due to turkey is more susceptible to AIV than chickens and ducks [27]. Additionally, it is worth mentioning that chickens are the predominant poultry species in LBMs. In the surveyed markets, the H9 positive cases in chickens $(87.5 \%)$ were higher than H5 (12.5\%). All positive cases in ducks and geese were related to HP H5 AIV, however, in turkeys the H5 and H9 positive cases were equal (Table 2). Kayali et al. [28] recorded that the incidence of $\mathrm{H} 5$ was higher than H9 in chickens and ducks but in geese and turkeys all positive cases were H5. Infection of ducks as an important waterfowl reservoir with HPAI is well documented worldwide either wild or domesticated ducks [29-31]. Moreover, waterfowl can be silently infected with H5N1 [32-36] which can maintain the virus in these markets for longer times. It is worth pointing out that, ducks are capable of excreting H5N1 HPAIV for at least 17 days via the cloacal and respiratory routes [37]. In addition, a close relationship of viruses from backyard ducks and humans was recorded [15, 17, 38-40]. Consequently, domestic ducks have been implicated in the spreading and evolution of H5N1 HPAIVs, and their inclusion in disease control programs is essential $[23,37,41]$. As a result, keeping different species of birds together in LBMs provides appropriate conditions for inter- and intra-species transmission $[15,42,43]$.

Regarding the role of season on the AIVs spread, the highest prevalence was identified during the winter season (2.4\%) (Table 3). Similarly, Abdelwahab et al. [15] recorded higher incidence of positive LBMs (40.8\%) during the cold month of February. Our results might be attributed to that the influenza A virus survival and viability are known to increase at lower environmental temperatures [44]. The virus spread decrease in summer due to hot weather and dryness. Thus, the disease is associated with cold weather due to favorable conditions for propagation and spread of the virus [44-48].

Table 4: Avian influenza positive cases in live bird markets concerning bird source (backyard flocks commercial farms)

\begin{tabular}{lcccccc}
\hline \multirow{2}{*}{ Species } & \multicolumn{2}{c}{ Backyard flocks } & \multicolumn{3}{c}{ Commercial farm } \\
\cline { 2 - 6 } & $\begin{array}{c}\text { positive } \\
\text { cases }\end{array}$ & \multicolumn{2}{c}{ AIV subtypes } & \multicolumn{2}{c}{ positive } & \multicolumn{2}{c}{ AIV subtypes } \\
& $2 / 8$ & $0 / 8$ & $2 / 8$ & $6 / 8$ & $1 / 8$ & $5 / 8$ \\
\hline Chickens & $0 / 2$ & $0 / 2$ & $0 / 2$ & $2 / 2$ & $2 / 2$ & $0 / 2$ \\
Ducks & $2 / 2$ & $2 / 2$ & $0 / 2$ & $0 / 2$ & $0 / 2$ & $0 / 2$ \\
Geese & $2 / 4$ & $1 / 4$ & $1 / 4$ & $2 / 4$ & $1 / 4$ & $1 / 4$ \\
Turkeys & $\mathbf{6 / 1 6}$ & $\mathbf{3 / 1 6}$ & $\mathbf{3 / 1 6}(\mathbf{1 8 . 8 \% )}$ & $\mathbf{1 0 / 1 6}$ & $\mathbf{4 / 1 6}$ & $\mathbf{6 / 1 6}$ \\
Total & $(\mathbf{3 7 . 5 \% )}$ & $\mathbf{( 1 8 . 8 \% )}$ & & $\mathbf{( 6 2 . 5 \% )}$ & $\mathbf{( 2 5 \% )}$ & $\mathbf{( 3 7 . 5 \% )}$ \\
& & & & & & \\
\hline
\end{tabular}


Concerning the geographical distribution of AIVs in the Suez Canal region, the highest positive cases were recorded in Ismailia Governorate $(9.8 \%)$ followed by Port Said $(3.2 \%)$, no positive cases were detected in Suez Governorate (Figure 1). These results might be due to high poultry production density in Ismailia Governorate. In relation to bird source/origin, the surveyed LBMs contain birds from both commercial farms (mostly chickens) and backyard flocks (mainly waterfowl). Higher positive cases were recorded in birds from commercial farms $(62.5 \%)$ than that from backyard flocks (37.5\%) (Table 4). Moreover, the H9 positive cases $(37.5 \%)$ in birds from commercial farms were higher than H5 (25\%). On the other hand, birds coming from backyard flocks, H5 and $\mathrm{H} 9$ positive cases were equal (18.8\%). The H9 positive cases in birds coming from commercial farms $(37.5 \%)$ were higher than those from backyard (18.8\%). No H7 positive cases were detected in the examined markets (Table 4).

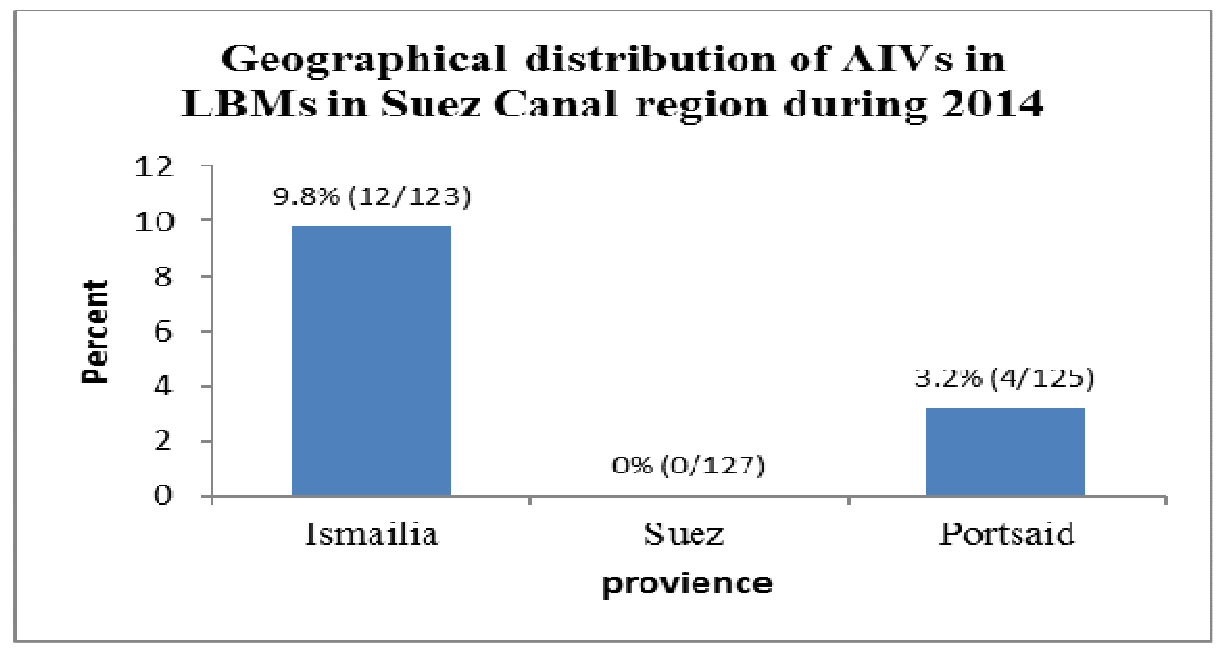

Figure 1: Geographical distribution of AIVs in LBMs in the Suez Canal region during 2014

Consequently, the wide spread of LP H9 AIV in birds coming from commercial farms might be due to the H9 AI vaccines are used in narrow scale in commercial poultry farms because some poultry producers thought that $\mathrm{H} 9$ vaccine is not essential. In addition to the low pathogenic nature of the virus, which permits its silent spread in commercial chickens [26]. Therefore, continuous surveillance in LBMs and incorporation of multifaceted strategies and global cooperation are required to control the virus spread in Egypt [17]. Birds in these markets came from different localities in Sharkia, Qlubiya, El Menya, and Ismailia Governorates. As a result, LBMs act as a mixing vessel due to the existence of various birds coming from different sources/origin (backyard flocks and commercial farms) also from different localities which permit transmission of the disease from infected areas to non-infected ones. Furthermore, LBMs are considered a high risk location of AIVs due to the coexistence of both H5 and H9 subtypes in the same poultry population which may provide an opportunity for genetic reassortment and emergence of novel viruses similarly to what has happened in Pakistan and Southern China in the recent past $[49,50]$.

The circulation of the AIVs in LBMs may be attributed to absence of biosecurity measures or any veterinary supervision in these markets. Moreover, the illegal transportation of birds between different localities.

\section{Conclusion}

Our findings revealed that LBMs in the Suez Canal region represent a high risk location of potential AIV transmission to commercial poultry and householders and thus are incriminated in the continuous dissemination of AIVs. Therefore, the authorities must make temporary or permanent 
closure of AI positive markets. In addition, veterinary supervision, biosecurity measures, prevention of the illegal transportation of poultry among different provinces, along with routine surveillance must be enforced in these markets.

\section{Conflict of interest}

The authors have any conflict of interest to declare.

\section{Acknowledgments}

Special thanks to the Food and agriculture organization (FAO) as this study was a part of project for studying $\mathrm{AI}$ in Egypt.

\section{References}

[1]Capua, I. and Alexander, D.J. (2004): Avian influenza: recent developments. Avian Pathol,, 33(4): 393-404.

[2]Palese, P. and Shaw, M.L. (2007): Orthomyxoviridae: The Viruses and Their Replication, In: D.M. Knipe and P.M. Howley (eds), Fields Virology $5^{\text {th }}$ ed. Lippincott Williams \& Wilkins, Philadelphia,P: 1647-1689.

[3]Tong, S.; Li, Y.; Rivailler, P.; Conrardy, C.; Castillo, D.A.; Chen, L.M.; et. al., (2012): A distinct lineage of influenza A virus from bats. Proc Natl Acad Sci USA, 109(11): 4269-4274.

[4] Tong, S.; Zhu, X.; Li, Y.; Shi, M.; Zhang, J.; Bourgeois, M.; et. al., (2013): New World bats harbor diverse influenza A viruses. PLoS Pathog. 9(10):e1003657.

[5] Aly, M.M.; Hassan, M.K. and Arafa, A. (2006): Emergence of highly pathogenic $\mathrm{H} 5 \mathrm{~N} 1$ avian influenza virus in poultry in Egypt: first record of 2006 outbreaks. J Egyt Vet Med Assoc, 66(2): 263-276.

[6] Aly, M.M.; Arafa, A. and Hassan, M. K. (2008): Epidemiological findings of outbreaks of disease caused by highly pathogenic $\mathrm{H} 5 \mathrm{~N} 1$ avian influenza virus in poultry in Egypt during 2006. Avian Dis, 52(2):269-277.

[7] Arafa, A.S.; Naguib, M.M.; Luttermann, C.; Selim, A.A.; Kilany, W.H.; Hagag, N.; et al., (2015): Emergence of a novel cluster of influenza $\mathrm{A}(\mathrm{H} 5 \mathrm{~N} 1)$ virus clade 2.2.1.2 with putative human health impact in Egypt, 2014/15. Eurosurveillance, 20(13), 21085.

[8]WHO World Health Organization (2015): Situation updates avian influenza (http://www.who.int/csr/disease/avian_infl uenza/updates/en/index.html). Accessed 20 November 2015.

[9]WHO World Health Organization (2016): Situation updates avian influenza (http://www.who.int/csr/disease/avian_infl uenza/updates/en/index.html).Accessed April 2016..

[10]El-Zoghby, E.F.; Arafa, A.S.; Hassan, M.K. ; Aly, M.M.; Selim, A.; Kilany, W.H.; et al., (2012): Isolation of H9N2 avian influenza virus from bobwhite quail (Colinus virginianus) in Egypt. Arch Virol, 157(6): 1167-1172.

[11]Perdue, M.L. and Swayne, D.E. (2005): Public health risk from avian influenza viruses. Avian Dis, 49(3): 317-327.

[12]Wan, H.; Sorrell, E.M.; Song, H.; Hossain, M.J.; Ramirez-Nieto, G.; Monne, I.; et. al.,(2008): Replication and transmission of H9N2 influenza viruses in ferrets: Evaluation of pandemic potential. PLoS One, 3(8):e2923.

[13]Matrosovich, M.; Krauss, S. and Webster R.G. (2001): H9N2 influenza A viruses from poultry in Asia have human viruslike receptor specificity. Virol, 281(2): 156-162.

[14] Ibrahim, A. A.; Albrechtsen, L.; Upton, M.; Morgan, N. and Rushton, J. (2007): Market Impacts of HPAI Outbreaks: a rapid appraisal process, Egypt 2007. Report submitted to FAO 2007. 33 pp.

[15] Abdelwhab, E.M.; Selim, A.A.; Arafa, A.; Galal, S.; Kilany, W.H.; Hassan, M.K.; Aly, M.M. and Hafez, M.H. (2010): Circulation of Avian Influenza H5N1 in Live Bird Markets in Egypt. Avian Dis, 54(2): 911-914.

[16] Hosny, F. (2009): Characterization of the poultry production sectors and identification of policy gaps for HPAI control in Egypt. A consultancy report for FAO-ECTAD, Egypt. In: FAO (Ed.) ECTAD, Cairo, Egypt. 
[17] El-Zoghby, E.F.; Aly, M.M.; Nasef, S.A.; Hassan, M.K.; Arafa, A.; Selim, A.A.; et. al., (2013): Surveillance on A/H5N1 virus in domestic poultry and wild birds in Egypt. Virol J, 10(1):203

[18] Fournié, G.; Guitian, F.J.; Mangtani, P. and Ghani, A.C. (2010): Impact of the implementation of rest days in live bird markets on the dynamics of H5N1 highly pathogenic avian influenza. J $\mathrm{R}$ Soc Interface; rsif20100510..

[19]OIE manual, (2008): Terrestrial Manual of Diagnostic Tests and Vaccines for Terrestrial Animals of Avian influenza http://www.oie.int/fileadmin/Home/eng/ Health_standards/tahm/2.03.04_AI.pdf Chapter 2.3.4.

[20] Spackman, E.; Senne, D.A.; Myers, T.J.; Bulaga, L.L.; Garber, L.P.; Perdue, M.L.; et. al., (2002): Development of a realtime reverse transcriptase PCR assay for type A influenza virus and the avian $\mathrm{H} 5$ and $\mathrm{H} 7$ hemagglutinin subtypes. J Clin Microbiol, 40(9): 3256-3260.

[21]Slomka, M.J.; Theo, P.; Coward, V.J; Voermans, J.; Koch, G.; Hanna, A.; Banks, J. and Brown, I.H. (2009): Validated real time reverse transcriptase PCR methods for the diagnosis and pathotyping of Eurasian $\mathrm{H} 7$ avian influenza viruses. Influenza Other Respi Viruses, 3(4): 151-164

[22] Ben Shabat, M.; Meir, R.; Haddas, R.; Lapin, E.; Shkoda, I.; Raibstein, I.; Perk, S. and Davidson, I. (2010): Development of a real-time TaqMan RT-PCR assay for the detection of H9N2 avian influenza viruses. J Virol Methods, 168(1): 72-77.

[23]Chen, H.; Deng, G.; Li, Z.; Tian, G.; Li, Y.; Jiao, P.; Zhang, L.; Liu, Z.; Webster, R.G. and Yu, K. (2004): The evolution of H5N1 influenza viruses in ducks in southern China. Proc. Natl. Acad. Sci. USA, 101:10452-10457.

[24]Bano, S.; Naeem, K. and Malik, S. A. (2003): Evaluation of pathogenic potential of avian influenza virus serotype H9N2 in chickens. Avian Dis, 47(suppl 3):817-822.
[25] Alexander, D. J. (2000): A review of avian influenza in different bird species. Vet Microbiol, 74(1): 3-13.

[26] Arafa, A.; Hagag, N.M.; Yehia, N.; Zanaty, A.M.; Naguib, M.M. and Nasef, S.A. (2012): Effect of Cocirculation of Highly Pathogenic Avian Influenza H5N1 Subtype with Low Pathogenic H9N2 Subtype on the Spread of Infections. Avian Dis, 56(Suppl 4): 849857.

[27]Tumpey, T.M.; Kapczynski, D.R. and Swayne, D.E. (2004): Comparative susceptibility of chickens and turkeys to avian influenza A H7N2 virus infection and protective efficacy of a commercial avian influenza $\mathrm{H} 7 \mathrm{~N} 2$ virus vaccine. Avian Dis, 48(1): 167-176.

[28]Kayali, G.; Kandeil, A.; El-Shesheny, R.; Kayed, A.S.; Gomaa, M.M.; Maatouq, A.M.; et. al., (2014): Active Surveillance for Avian Influenza Virus, Egypt, 2010 2012. Emerg Infect Dis, 20(4): 542-551

[29] Perkins, L.E. and Swayne, D.E. (2002): Pathogenicity of a Hong Kong origin H5N1 highly pathogenic avian influenza virus for emus, geese, ducks, and pigeons. Avian Dis, 46(1):53-63.

[30]Sturm-Ramirez, K.M.; Ellis, T.; Bousfield, B.; Bissett, L.; Dyrting, K.; Rehg, J.E.; et al.,(2004): Reemerging H5N1 influenza viruses in Hong Kong in 2002 are highly pathogenic to ducks. J Virol, 78(9): 4892-4901.

[31]Gilbert, M.; Chaitaweesub, P.; Parakamawongsa, T.; Premashthira, S.; Tiensin, T.; Kalpravidh, W.; et. al., (2006): Free-grazing ducks and highly pathogenic avian influenza, Thailand. Emerg Infect Dis., 12(2):227-234.

[32]Chen, H.; Bu, Z. and Wang, J. (2008): Epidemiology and Control of H5N1 Avian Influenza in China. In Avian influenza Monogr Virol Basel. $1^{\text {st }}$ edition volume 27. Edited by: Klenk H-D, Matrosovich MN, Stech J. Karger; 2008:27-40.

[33]Hassan, M.K.; Jobre, Y.; Arafa, A.; Abdelwhab, E.M.; Kilany, W.H.; Khoulosy, S.G.; et. al., (2013): 
Detection of $\mathrm{A} / \mathrm{H} 5 \mathrm{~N} 1$ virus from asymptomatic native ducks in midsummer in Egypt. Arch Virol, 158(6): 1361-1365.

[34] Joannis, T.M.; Meseko, C.A.; Oladokun, A.T.; Ularamu, H.G.; Egbuji, A.N.; Solomon, P.; et. al., (2008): Serologic and virologic surveillance of avian influenza in Nigeria, 20067. EuroSurveill, 13(42): 19007.

[35] Liu, M.; He, S.; Walker, D.; Zhou, N.; Perez, D.R.; Mo, B.; et. al., (2003): The influenza virus gene pool in a poultry market in South central china. Virol, 305(2): 267-275.

[36] Nguyen, D.C.; Uyeki, TM.; Jadhao, S.; Maines, T.; Shaw, M.; Matsuoka, Y.; et. al., (2005): Isolation and characterization of avian influenza viruses, including highly pathogenic $\mathrm{H} 5 \mathrm{~N} 1$, from poultry in live bird markets in Hanoi, Vietnam, in 2001. J Virol, 79(7): 4201-4212.

[37] Hulse-Post, D.J.; Sturm-Ramirez, K.M.; Humberd, J.; Seiler, P.; Govorkova, E.A.; Krauss, S.; et al., (2005): Role of domestic ducks in the propagation and biological evolution of highly pathogenic H5N1 influenza viruses in Asia. Proc Natl Acad Sci USA 102:10682-10687.

[38]Abdelwhab, E.M.; Arafa, A.; Stech, J.;Grund, C.; Stech, O.; GraeberGerberding, M.; et. al., (2012): Diversifying evolution of highly pathogenic $\mathrm{H} 5 \mathrm{~N} 1$ avian influenza virus in Egypt from 2006 to 2011. Virus Genes, 45(1): 14-23

[39]Arafa, A.; Suarez, D.L.; Hassan, M.K. and Aly, M.M. (2010): Phylogenetic analysis of HA and NA genes of HPAI-H5N1 Egyptian strains isolated from 2006 to 2008 indicates heterogeneity with multiple distinct sublineages. Avian Dis, 54: 345-349.

[40] Arafa, A.; Suarez, D.; Kholosy, S.G.; Hassan, M.K.; Nasef, S.; Selim, A.; et al., (2012): Evolution of highly pathogenic avian influenza $\mathrm{H} 5 \mathrm{~N} 1$ viruses in Egypt indicating progressive adaptation. Arch Virol, 157(10): 19311947
[41]Swayne, D.E. (2006): Principles for vaccine protection in chickens and domestic waterfowl against avian influenza: emphasis on Asian H5N1 high pathogenicity avian influenza. Ann N Y Acad Sci, 1081(1):174-181.

[42] Mohan, R.; Saif, Y.M.; Erickson, G.A.; Gustafson, G.A. and Easterday, B.C. (1981): Serologic and epidemiologic evidence of infection in turkeys with an agent related to the swine influenza virus. Avian Dis, 25: 11-16.

[43] Swayne, D.E. (2000): Understanding the ecology and epidemiology of avian influenza viruses: implications for zoonotic potential. In: C. Brown, and C. A. Bolin, eds. Emerging diseases of animals. ASM Press, Washington, DC. pp. 101-130.

[44]Li, K.S.; Guan, Y.; Wang, J.; Smith, G.J.D.; Xu, K.M.; Duan, L.; et al., (2004): Genesis of a highly pathogenic and potentially pandemic $\mathrm{H} 5 \mathrm{~N} 1$ influenza virus in Eastern Asia. Nature, 430(6996): 209-213.

[45]Halvorson, D.A.; Kelleher, C.J. and Senne, D.A. (1985): Epizootiology of avian influenza: effect of season on incidence in sentinel ducks and domestic turkeys in Minnesota. Appl Environ Microbiol, 49(4): 914-919.

[46]Cheng, M.C.; Wang, C.H. and Kida, H. (2004): Influenza A virological surveillance in feral waterfowl in Taiwan from 1998 to 2002. Int Congr Ser,1263: 745-748.

[47]Aly, M.M.; Kanawaty, Z.; Arafa, A.; Kilany, W.H. and Abdelwhab, E.M. (2007): One-year surveillance on avian influenza $\mathrm{H} 5 \mathrm{~N} 1$ in backyard poultry in Egypt. Proceedings of the $4^{\text {th }}$ International Symposium of Turkey Production, Berlin, Germany: 294-306.

[48]Suarez, D.L. (2008): Avian influenza. Pages 3-22 in Avian Influenza. D.E. Swayne, ed. Blackwell Publishing, Ames, IA.

[49]Iqbal, M.; Yaqub, T.; Reddy, K., and McCauley, J.W. (2009): Novel genotypes of H9N2 influenza A viruses 
isolated from poultry in Pakistan containing NS genes similar to highly pathogenic $\mathrm{H} 7 \mathrm{~N} 3$ and $\mathrm{H} 5 \mathrm{~N} 1$ viruses. PLoS One, 4(6):e5788.
[50] Dong, G.; Xu, C.; Wang, C.; Wu, B.; Luo, J.; Zhang, H.; et al., (2011): Reassortant H9N2 influenza viruses containing H5N1-like PB1 genes isolated from black-billed magpies in Southern China. PLoS One, 6(9):e25808.

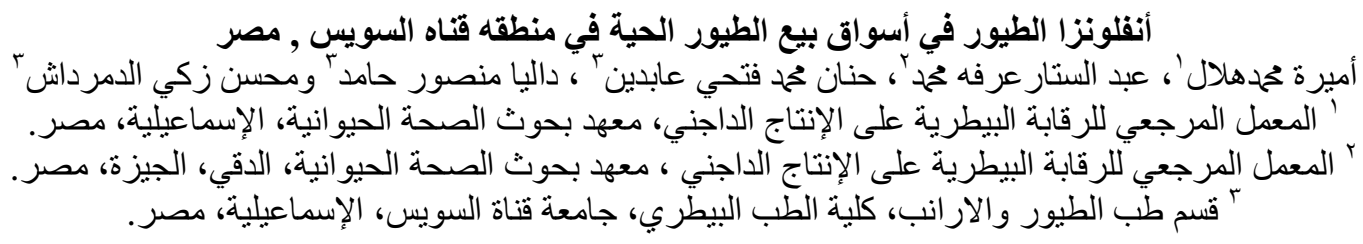

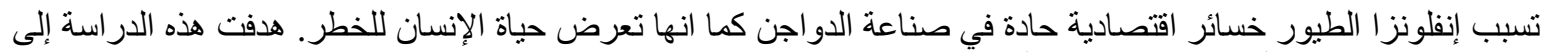

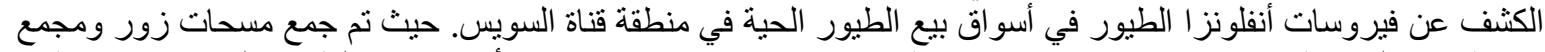

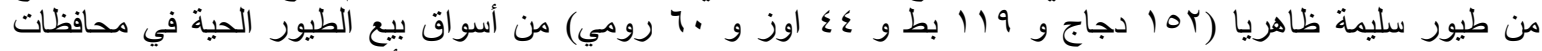

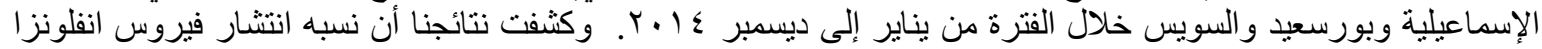

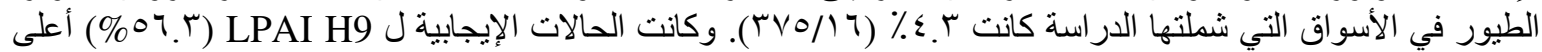

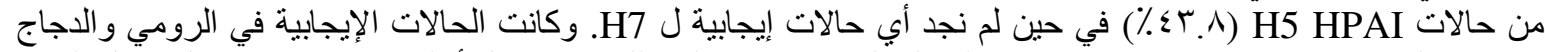

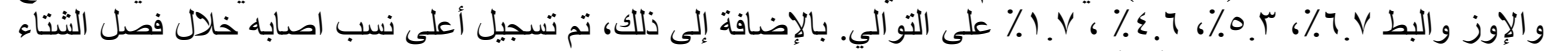

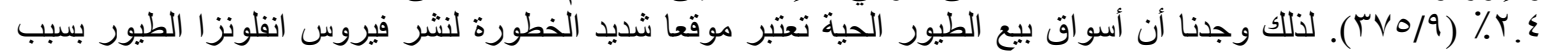

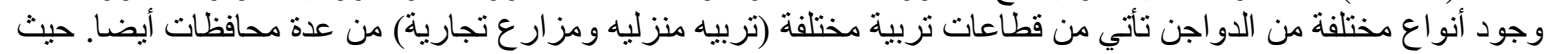

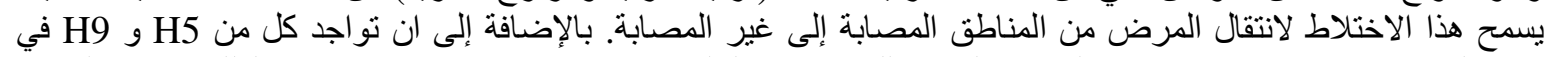

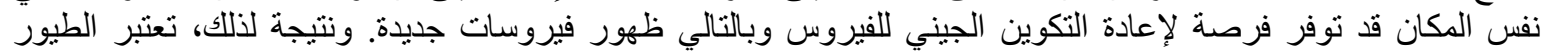

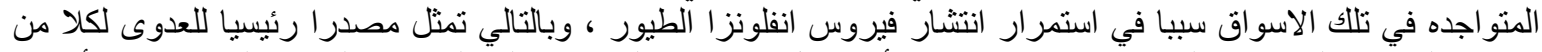

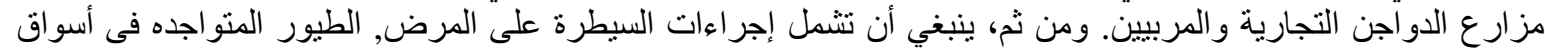

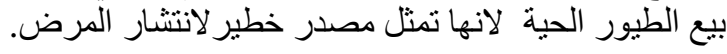

